\title{
IMAGES OF JUSTICE
}

$2^{\text {nd }}$ ed. Children \& Human Rights

Curated by Omid Milani

The $2^{\text {nd }}$ edition of Images of Justice, a satirical cartoon series on human rights issues, sheds light on the current discourse on the rights of the child through exhibiting brilliant and critical work of political cartoonists from around the world, including Bruce MacKinnon from Canada, Luc Descheemaeker from Belgium, Valentin Georgiev from Bulgaria, Silvano Mello from Brazil, and Keyvan Varesi from Iran. This edition is a partnership amongst CONTEKST, a research project on the Image and Law's relationship, the Human Rights Research and Education Centre (University of Ottawa), the Interdisciplinary Research Laboratory on the Rights of the Child (University of Ottawa), the School of Child and Youth Care (Ryerson University), as well as the Landon Pearson Resource Centre for the Study of Childhood and Children's Rights (Carleton University). For the exhibit's online gallery visit https://contekst.education/exhibits/images-of-justice/ 


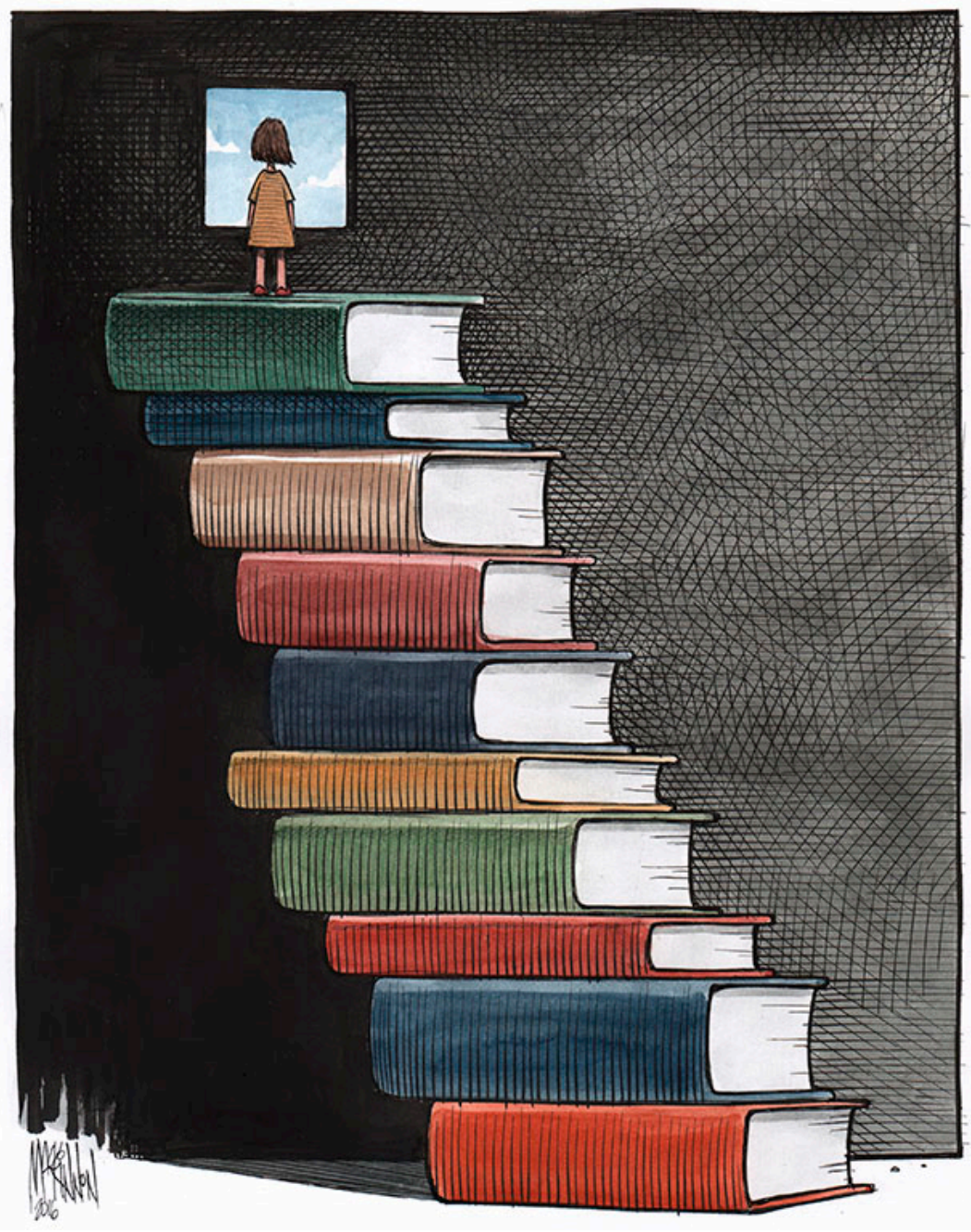

Bruce MacKinnon 


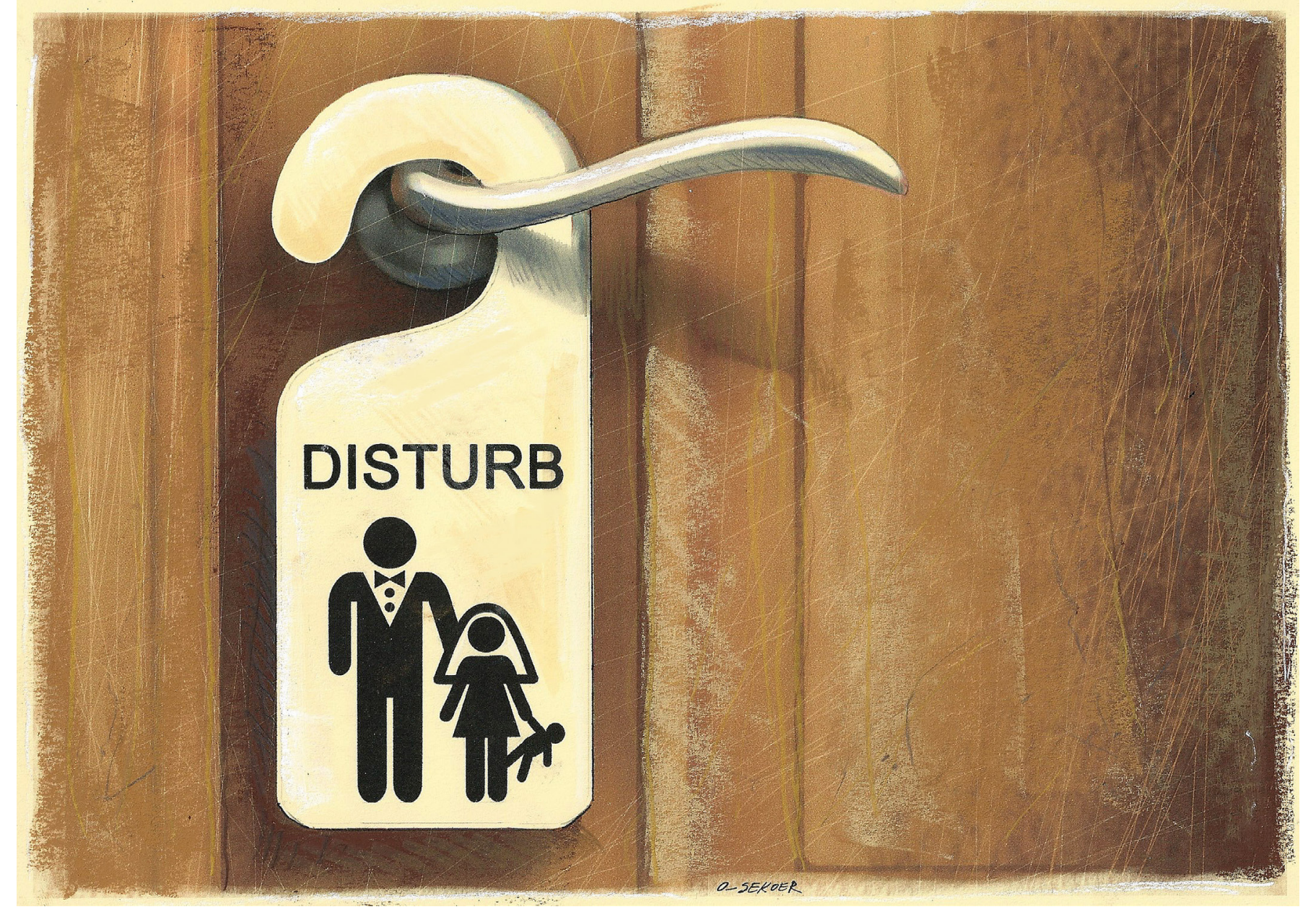

Luc Descheemaeker (O-SEKOER) 


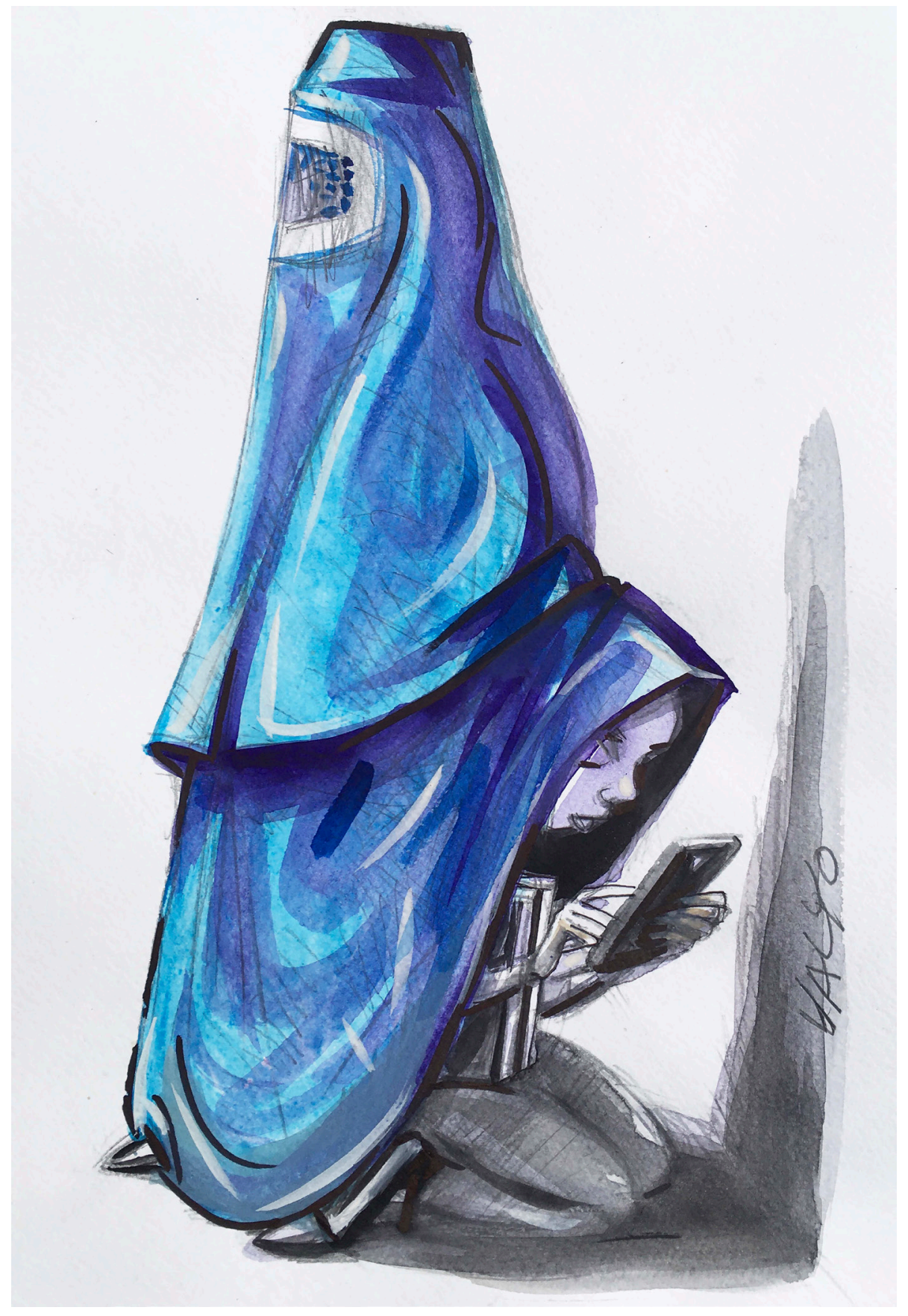

Valentin Georgiev 

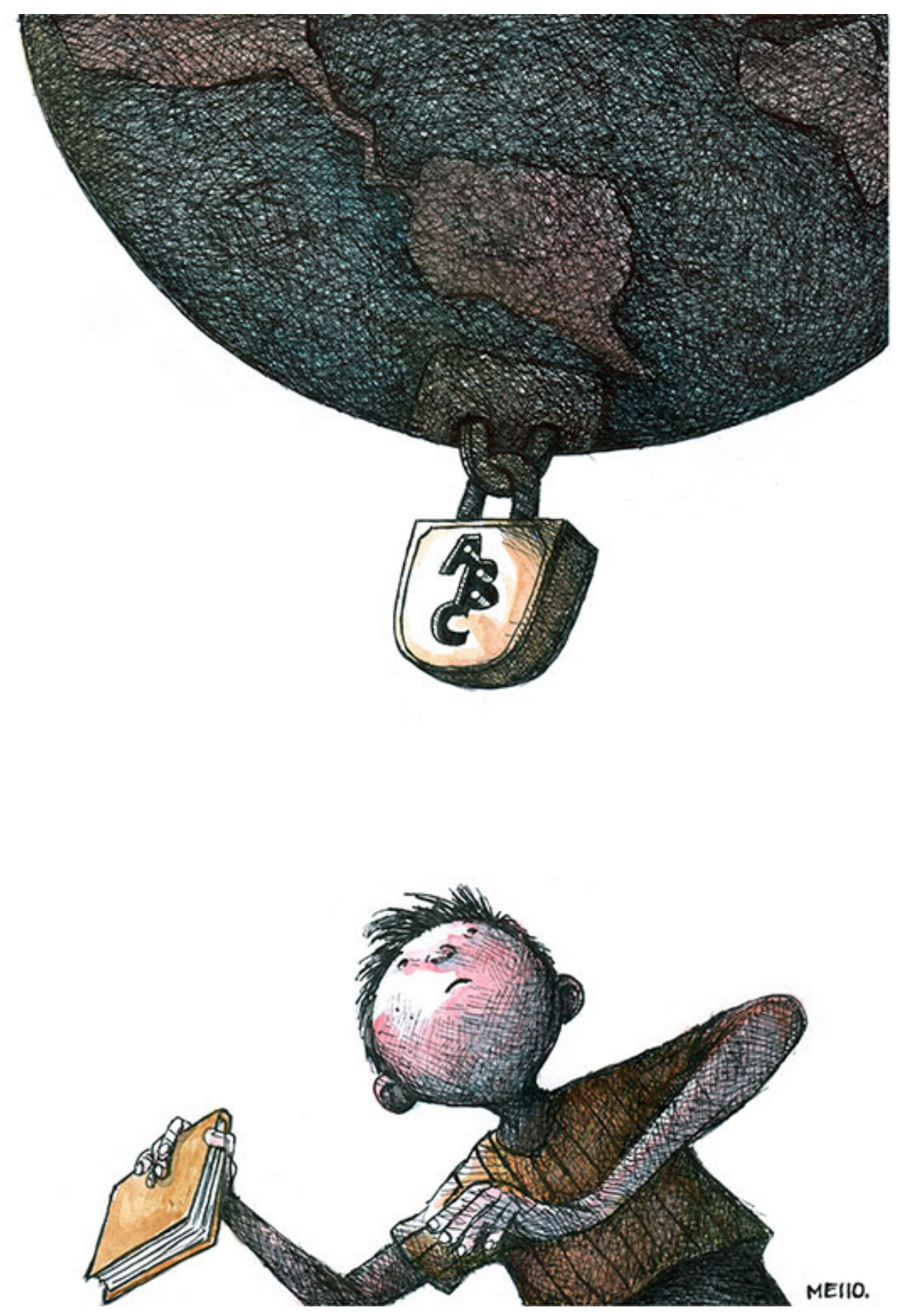

Silvano Mello 


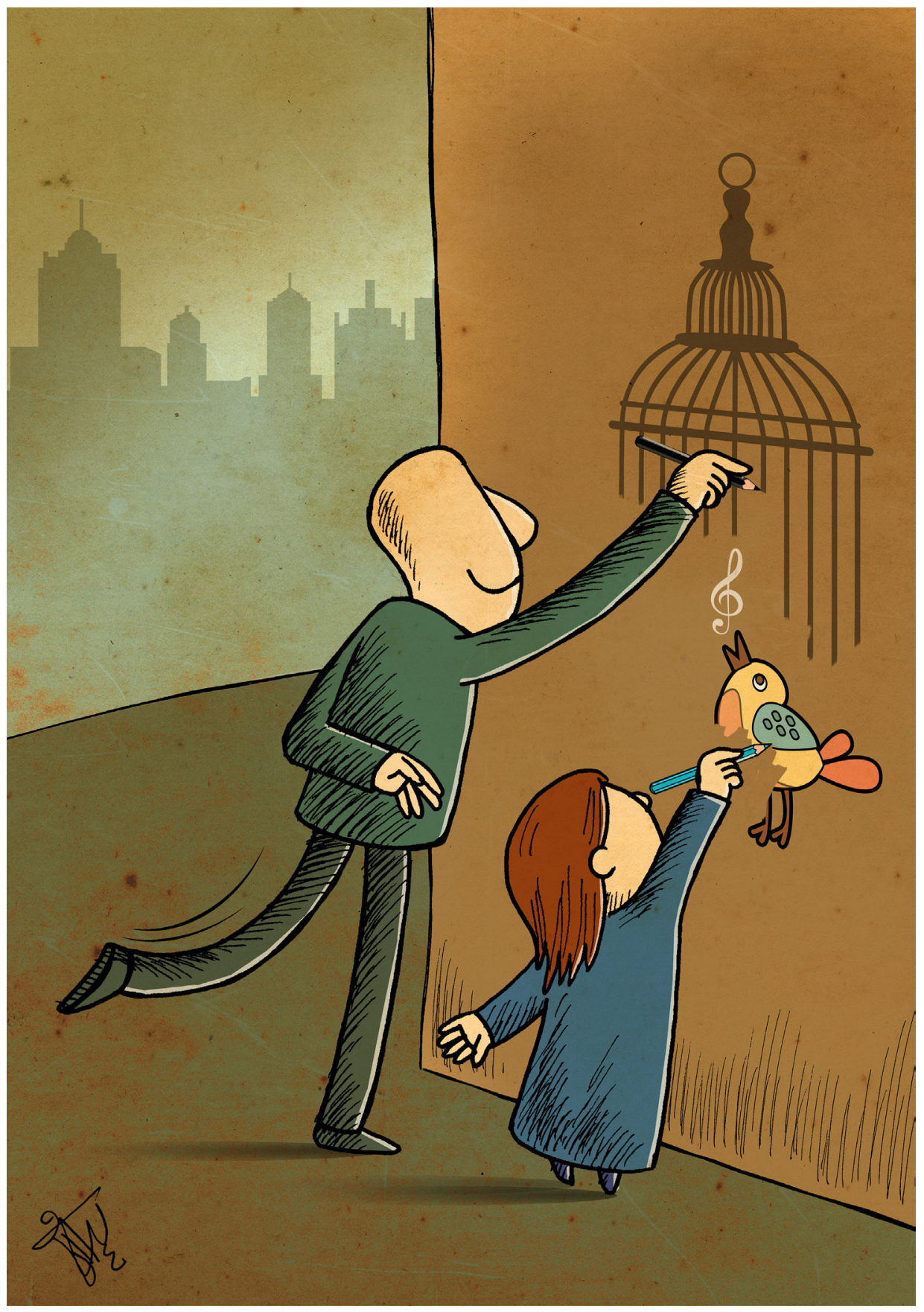

Keyvan Varesi 